\title{
Relationship between Emotional Intelligence and Marital Satisfaction of Male and Female Married Teachers in Anambra State
}

\author{
Anyamene, Ada, PhD \\ Etele, Anulika Valentina, MEd \\ Nnamdi Azikiwe University, Awka
}

Doi:10.19044/ejes.v7no3a1 URL:http://dx.doi.org/10.19044/ejes.v7no3a1

\begin{abstract}
Marriages a bond between a man and a woman that is supposed to produce a satisfactory relationship whereby the married couple experience marital satisfaction that brings about mental and physical health of the individuals. This study determined the relationship between emotional intelligence and marital satisfaction of married teachers in Anambra state.three research questions were formulated to guide the study while three null hypotheses were tested at 0.05 level of significance. Correlational research design was adopted for the study. A sample size of 1,344 married teachers was drawn from a population of 6,987 married teachers. A multi-stage sampling procedure was followed selecting the sample. Two instruments: Emotional intelligence Scale (EIS) and Index of Marital Satisfaction (IMS) were adopted and used for data collection. The instruments are standardised measures and have the following reliability coefficient; 0.96 for IMS, 0.89 and for EIS. Data was collected through direct delivery approach. Data collected were analysed. Pearson correlation coefficients and regression analysis were used to answer research questions and test the hypotheses. Findings of the study showed among others that there is a significant low relationship existing among married teachers' emotional intelligence and their marital satisfaction. Based on the findings of the study, it was recommended, among others that married teachers should be encouraged by the Counselors involved in marital counselling to pursue habits and attitudes that promote marital satisfaction through periodic seminars and counseling sessions.
\end{abstract}

Keywords: Emotional intelligence, marital satisfaction, married teachers, relationship, Anambra state. 


\section{Introduction}

Marriage is one of the most important stages in the development path of personal and social lives of individuals. It is considered as the most important social unit, which many factors are involved in its stability and strength. Hence, the quality of marriage as described by Khorasani, Hosseini, Matbouei, Khafri, Vasli and Vardanjani (2017) is the most powerful factor predicting the psychological health of married persons. The married peoples' relationship and their satisfaction of marital life according to Khorasani et al. is one of the important factors which determine the fate of their marriage.

The term marriage according to Odebunmi (2007) referred to the union of man and woman as husband and wife, which constitute the basic and essential unit of the society. As a physical as well as a moral union, marriage is recognized by society as the basis of a family. It may be a sacrament and in that way an indissoluble union for this life and hereafter, or a temporary civil contract for a fixed period. Nonetheless, whether a sacrament or a civil contract, the relationship, above sexual satisfaction, include, joining two members of opposite sexes for the procreation of legitimate children. While particular marriages may, of course, be entered into for any number of other reasons as family pleasure, social conveniences, financial considerations and similar motives, basically the prime objects of marriage are usually companionship, sexual intimacy and procreation.

Marriage in whatever form it exists is usually a source of satisfaction and gratification for many individuals in marital relationship. Satisfactory marriage for these people according to Omage (2013) is a shield against mental pressures and negative life events, while unstable and unsatisfactory marriages have negative consequences for both physical and mental health. Thus, healthy marriages need to be composed of a cordial relationship that could lead to marital satisfaction.

Marital satisfaction could be seen as an individual's positive assessment of his/her marital relations. It is a state of satisfaction in marriages which is defined by the intra personal or interpersonal perception. Hence, it is seen as a measure that shows how much a person's feeling and needs are met (Ja'farzadeh, 2011). Moreover, in the context of this study, marital satisfaction refers to an individual's positive assessment of his/her contentment with marital relations in terms of how much the individual's feelings and needs are being met.

A number of determinants are associated with marital satisfaction amongst which are compatibility of personality, educational homogamy, religious homogamy, and income level, level of education, age at marriage, and age of marriage. Thus, in today's society, meeting the needs of partners in marital relationship seems to be becoming a daunting task. The case of married teachers is not different as many seems to be coping with a large number of 
problems to get their partners to make a relationship, preserve intimate relationships, and understand each other's emotions. A married teacher in the context of this study is a person (male or female) who is in a legally bound union and is engaged in a school to teach as a profession. For such a person, it is assumed that the significance of marriage in the individual's life has the prospect of affecting other facets of life such as the physical and psychological health.

One being in a satisfactory marriage has consistently been associated with better physical health, mental health, and overall life satisfaction. This assumption is supported by Mohammadimehr and Ayatollah (2017) who noted that satisfactory marriage is a shield against mental pressures and negative life events, while unstable and stressful marriages have negative consequences for physical and mental health. This research evidence thus indicated that some of the marital encounters and problems are related to inabilities for maintaining sincere relationship and misunderstanding between married people; as well as other factors such as economic, cultural, and social factors which tend to provide inappropriate and bad effects in their common life. In similar way, when there is no problem in a marital life, people would likely report a high level of satisfaction in their marriages.

Although marriage could be described as a pleasing bond, Mohammadimehr and Ayatollah (2017) observation on the other hand, shows that there is no perfect marriage, as more than half of the marriages in recent times are likely to lead to disappointment and separation. So, as more married people report lack of satisfaction and some seek for dissolution of their marriages, the concern of scholars has led to many research efforts (such as Lavalekar, Kulkarni \& Jagtap, 2010; Ofovwe1, Ofili, Ojetu \& Okosun, 2013), which was geared towards figuring out the elements that influence the level of satisfaction and persistency in marital interpersonal relationships.

Lavalekar, Kulkarni and Jagtap, Ofovwe1, Ofili, Ojetu and Okosun (2013) study focused on observable inter and intrapersonal factors in everyday communication of married people that are happy with each other. The researchers observed that factors like emotional awareness, emotional expression, emotional regulation, and sympathy affect the marriage communication and quality, which is perceived as a pointer to marital satisfaction.

From Lavalekar, et al. point of view, an unsatisfactory marriage is a function of many factors. A marriage may be in crisis if one or more of the four purposes of marriage namely childbearing, sexual satisfaction, companionship and economic satisfaction are not satisfactorily achieved. What this means is that marital satisfaction is a sub set of needs, and most of married persons, for different reasons seem not to care about that, while some are believed to be simply naive to basic principles and tenets to a satisfactory 
marital life. For instance, some married teachers, due to the nature of their job which involves constant marking of test scripts and recording, tend to extend their work beyond classroom to their homes. When this happens, the time married people should spend together would be taken over by school jobs, hence interfering in their relationship. This may continue over time and may eventually lead to failure to properly identify and meet the needs of a spouse. According to Anghel (2016), happiness, emotional awareness and selfactualization are most strongly related to marital satisfaction. The reason for this perhaps is based on the notion that married peoples' intimate relationship needs communication skills such as: paying attention to the other person's viewpoint, being able to empathize perception with what their partner has experienced, and also being sensitive and aware of the other persons need. Consequently, it becomes clearer that the educational intelligence of teachers alone may not guarantee their marital success in long-term, so other features are necessary for proper human relations and success in life that are referred to as emotional intelligence.

As a kind of capability, emotional intelligence consists of capacity perception and stating, recognizing, applying and managing self-emotions and emotions by others. Emotional intelligence according to Egbule (2009) is the ability to validly reason with emotions and to use emotions to enhance thought. It involves the ability to utilize emotional knowledge to accurately observe, understand, generate, access and assist feelings or emotions so as to promote emotional and intellectual growth. Thus, in the context of this study, emotional intelligence refers to the married teachers' ability to monitor, recognise, understand, each other's feeling and be able to manage their thoughts and emotions and that of their partner.

Furthermore, Salovey and Mayer (1990) theoretical structure of emotional intelligence includes many positive experimental characteristics that researchers relate to the quality of marriage. Even more in particular, by thinking into his own and others' emotions, people can share the emotions and understand and manage the emotional information. Consequently, the more skills married people learn, the more they are likely to improve their communications and insight, thereby enhancing good understanding and proper management of the emotion of each other in the marital union.

Evidence suggests that in today's societies, couples have many pervasive problems establishing and maintaining a friendly relationship and understanding of their spouse's feelings. It is evident that deficits in the emotional and emotional qualities of spouses will have undesirable effects on their marital life, in addition to a number of other factors, such as economic, cultural and social factors). Ilyas and Habib (2014) for instance explored the relationship of marital satisfaction and emotional intelligence among different 
professionals. Findings of the study indicated significant relationship between marital satisfaction and emotional intelligence.

Emotional intelligence from the foregoing could thus play a significant role in a happier relationship and a more stable marriage. In life, often faced with difficulties, feelings of failure, humiliation among others, spouses tend to consider feelings and emotions rather than wisdom and reasoning. Recognizing and directing emotions may also make a major contribution to sustaining a marital partnership. While focusing on the effects of emotional intelligence on marital satisfaction does not mean overlooking those other factors, it is essential for the health of couples' emotional and social communication, family mental health and many basic family issues. Consideration needs to be given to the attributes in order to foster emotional maturity in order to achieve a better process of marital relationship.

One of the factors that is related to, and can play a role in the marital satisfaction is the demographic factor which focuses on the couple's gender. Gender plays an important role in many aspects of life and the relationship between a woman and man. Women and men have different views about marital satisfaction. In a women's view, communication, understanding, family relationships, agreement, and income by both spouses are effective factors in marital satisfaction, while in a man's opinion, spouse's education, income by both spouses, understanding, agreement, family relationships, and communication are effective factors in creating satisfaction.

There is a growing body of research findings indicating that gender is a functional component of emotional intelligence in management of the emotion in the marital union. For instance, Brackett, Warner and Bosco (2005) in their study observed that women's scores in emotional intelligence scales has more meaningful relationship with the quality of communication, as compared to those of the men. On the other hand, Agha, Mokhtaree, Sayadi, Nazer and Mosavi (2012) asserted that there was no meaningful difference between men and women's emotional intelligence.

Consequently, the deficiencies in emotional and affection competence of married teachers would likely have unpleasant effects on their matrimonial life. Some of these deficiencies according to Khorasani et al. (2017) include inability in self-consciousness, lack of self-control, lack of sympathy and the inability to sympathize with each other, and in general, deficiency in establishing a fruitful relationship. Since emotional quotient and self-efficacy are total of an individual's personality, management of emotions, understanding others, making a correlation between emotional intelligence, self-efficacy and marital satisfaction is quite meaningful.

Moreover, studies such as Gharahhajlou, Mirzaian, Hassanzadeh (2015) investigated the relationship between emotional intelligence and marital satisfaction among high school English teachers. Zadeh and Tabrizi 
(2014) also studies indicated a positive relationship between emotional intelligence and marital satisfaction of the teachers while Tamaren (2010) observe a dependency and a correlation between the dimensions of emotional intelligence and satisfaction. These studies though related to the current study were however done outside the shores of Nigeria. Research in this area of study is needed in Nigeria, especially here in Anambra State, and would help give better clarification on the relationship between emotional intelligence and marital satisfaction of married secondary school teachers. This will add to the knowledge of what contributes to marital satisfaction and happiness of married secondary school teachers in the state. This therefore instigated the need for this study.

\section{Purpose of the Study}

The main purpose of this study is to determine the relationship between emotional intelligence and marital satisfaction of married teachers in Anambra state. Specifically, the study intends to determine:

1. The relationship between the emotional intelligence and marital satisfaction of married teachers in Anambra State secondary schools.

2. The relationship between the emotional intelligence and marital satisfaction of married male and female teachers in Anambra State secondary schools.

\section{Significance of the Study}

Findings from this study will be beneficial to the married couples, Guidance Counsellors, singles intending to get married, parents, government, and future researchers. More importantly the findings, of the study will help increase married peoples' belief in their abilities to solve daily and communicational problems. Also, belief in their abilities can improve the quality of marriage relationship thereby leading to more satisfaction experience of marriage relationship among the married people. The findings of the study will further encourage married people to put their emotional intelligence to use in addressing persisting issues together when disagreements and problems occur.

Furthermore, findings of this study will benefit the Guidance Counsellors, psychologists and therapists. Through the findings of this study, they will likely be equipped with the knowledge of the relationship between the variables; emotional intelligence and marital satisfaction. The knowledge of the relationship between these variables will help the guidance counsellors in understanding how these factors interplay in fostering existence of mutual understanding between married couples. Thereby enabling the guidance counsellors to be in position to give emphasis on openness and trust among 
the married people, and the need to initiate an effective communication to enhance friendliness.

\section{Research Questions}

The following research questions guided the study.

1. What type of relationship exists between emotional intelligence and marital satisfaction of married teachers in Anambra State secondary schools? 2. What type of relationship exists between emotional intelligence and marital satisfaction of married male teachers in Anambra State secondary schools?

3. What type of relationship exists between emotional intelligence and marital satisfaction of married female teachers in Anambra State secondary schools?

\section{Hypotheses}

The following null hypotheses were formulated to guide the study and were tested at 0.05 level of significance.

1. The type of relationship existing between emotional intelligence and marital satisfaction of married teachers in Anambra State secondary schools is not significant.

2. The type of relationship existing between emotional intelligence and marital satisfaction of married male teachers in Anambra State secondary schools is not significant.

3. The type of relationship existing between emotional intelligence and marital satisfaction of married female teachers in Anambra State secondary schools is not significant.

\section{Method:}

\section{Research Design}

The study was conducted using a correlational research design. The design was used because it sought to establish the relationship that exists between variables; emotional intelligence and marital satisfaction of married teachers in Anambra State.

\section{Participants}

A total 1,344 married public secondary school teachers, made up of 144 male teachers and 1,200 female teachers from both public secondary schools in Anambra State made up the sample for this study. In selecting the sample for the study, A multi-stage sampling approach was used. 


\section{Instrument for Data Collection}

Two research instruments were used in this study to elicit information from the married school teachers. The instruments include: Emotional intelligence Scale (EIS) and Index of Marital Satisfaction (IMS). The Emotional Intelligence scale is a modified version of the emotional intelligence scale developed and standardized by Singh (2002) and was used to assess the emotional balance of the married teachers in dealing with issues related to their marriage. The instrument measures the self-awareness, selfregulation, self-motivation and social skills of the married teachers. Index of Marital Satisfaction (IMS) is a standardised instrument designed by Walter W. Hudson (1982) adapted in this study for Nigerian use. The Index of Marital Satisfaction (IMS), scale was designed to measure the degree, severity, or magnitude of the problem a spouse or partner has in a partner relationship. The IMS measures the magnitude of marital discord or dissatisfaction that is felt or perceived by one partner. The two instruments have all been subjected to internal consistency reliability test using Cronbach Alpha. The outcome yielded a coefficient Alpha of 0.89. for EIS and 0.96. for IMS..

\section{Data Collection and Analysis}

All the participants for the study were administered the two research instruments through direct delivery approach. The data collected for the research questions were analysed using Pearson Product Moment Correlation Coefficient (Pearson $r$ ), while t-test was used to test the null hypothesis.

\section{Findings:}

In this section, the data collected from the field for this study were analysed and the summaries presented in tables and charts to highlight the findings as follows:

\section{Research Question 1}

What type of relationship exists between emotional intelligence and marital satisfaction of married teachers in Anambra State secondary schools?

Table 1: Pearson $r$ on emotional intelligence and marital satisfaction of married teachers in Anambra State secondary schools

Source of Variation $\quad \mathrm{N}$ Emotional Intelligence $\mathrm{r}$ Marital Satisfaction r Remark

\begin{tabular}{lcccc}
\hline $\begin{array}{l}\text { Emotional Intelligence } \\
\text { Positive Relationship }\end{array}$ & 1322 & 1.00 & 0.20 & Low \\
Marital Satisfaction & 1322 & 0.20 & 1.00 & \\
\hline
\end{tabular}

In table 1, it was observed that low positive relationship of 0.20 exists between married teachers' Emotional Intelligence and their marital satisfaction. 


\section{Research Question 2}

What type of relationship exists between emotional intelligence and marital satisfaction of married male teachers in Anambra State secondary schools?

Table 2: Pearson $r$ on emotional intelligence and marital satisfaction of married male teachers in Anambra State secondary schools

Source of Variation $\quad \mathrm{N}$ Emotional Intelligence $\mathrm{r}$ Marital Satisfaction r Remark

\begin{tabular}{lcccc}
\hline $\begin{array}{l}\text { Emotional Intelligence } \\
\text { Positive Relationship }\end{array}$ & 143 & 1.00 & 0.26 & Low \\
Marital Satisfaction & 143 & 0.26 & 1.00 & \\
\hline
\end{tabular}

In table 2, it was observed that low positive relationship of 0.26 exists between married male teachers' Emotional Intelligence and their marital satisfaction.

\section{Research Question 3}

What type of relationship exists between emotional intelligence and marital satisfaction of married female teachers in Anambra State secondary schools?

Table 3: Pearson $r$ on emotional intelligence and marital satisfaction of married female teachers in Anambra State secondary schools

Source of Variation $\mathrm{N}$ Emotional Intelligence $r$ Marital Satisfaction $r$ Remark

\begin{tabular}{lllll}
\hline Emotional Intelligence & 1179 & 1.00 & 0.18 & Very
\end{tabular}

Low Positive Relationship

Marital Satisfaction 1179

$0.18 \quad 1.00$

Table 3 reveals that very low positive relationship of 0.18 exists between married female teachers' Emotional Intelligence and their marital satisfaction.

\section{Testing the Null Hypotheses}

\section{Null Hypothesis 1}

The type of relationship existing between emotional intelligence and marital satisfaction of married teachers in Anambra State secondary schools is not significant.

Table 4: t-test on the relationship existing between emotional intelligence and marital satisfaction of married teachers in Anambra State secondary schools

\begin{tabular}{lllrrc}
$\mathrm{N}$ & cal.r & df & Cal.t & Pvalue & Remark \\
\hline 1322 & 0.22 & 1320 & 2.81 & 0.006 & $\mathrm{~S}$ \\
\hline
\end{tabular}

$\mathrm{S}=$ Significant 
Table 4 indicates that at 0.05 level of significance and 1320df, the calculated t 2.81 with Pvalue 0.006 which is less than 0.05 , the first null hypothesis is rejected. The relationship existing between emotional intelligence and marital satisfaction of married teachers in Anambra State secondary schools is significant.

\section{Null Hypothesis 2}

The type of relationship existing between emotional intelligence and marital satisfaction of married male teachers in Anambra State secondary schools is not significant.

Table 5: t-test on the relationship existing between emotional intelligence and marital satisfaction of married male teachers in Anambra State secondary schools

\begin{tabular}{llrccc}
$\mathrm{N}$ & Cal.r & df & Cal.t & Pvalue & Remark \\
\hline 143 & 0.26 & 141 & 4.58 & 0.000 & $\mathrm{~S}$ \\
\hline
\end{tabular}

$$
\mathrm{S}=\text { Significant }
$$

Table 5 reveals that at 0.05 level of significance and 141df, the calculated t 4.58 with Pvalue 0.000 which is less than 0.05 , the third null hypothesis is rejected. The relationship existing between emotional intelligence and marital satisfaction of married male teachers in Anambra State secondary schools is significant.

\section{Null Hypothesis 3}

The type of relationship existing between emotional intelligence and marital satisfaction of married female teachers in Anambra State secondary schools is not significant.

Table 6: t-test on the relationship existing between emotional intelligence and marital satisfaction of married female teachers in Anambra State secondary schools

\begin{tabular}{llrccc}
$\mathrm{N}$ & Cal.r & df & Cal.t & Pvalue & Remark \\
\hline 1179 & 0.18 & 1177 & 4.95 & 0.000 & $\mathrm{~S}$ \\
\hline
\end{tabular}

$$
\mathrm{S}=\text { Significant }
$$

In table 6 , it was observed that at 0.05 level of significance and $1177 \mathrm{df}$, the calculated t 4.95 with Pvalue 0.000 which is less than 0.05 , the fourth null hypothesis is rejected. The relationship existing between emotional intelligence and marital satisfaction of married female teachers in Anambra State secondary schools is significant. 


\section{Discussions}

Findings of the study are discussed under the following sub-themes:

\section{The Relationship between the Emotional Intelligence and Marital Satisfaction of Married Teachers in Anambra State}

Findings of the study revealed that there is low positive relationship existing between married teachers' Emotional Intelligence and their marital satisfaction. The finding also indicated that the relationship existing between emotional intelligence and marital satisfaction of married teachers in Anambra State secondary schools is significant. The low positive relationship observed in the study indicates that with an increase in the married teachers' emotional intelligence, there would be a corresponding slight increase their marital satisfaction and the relationship is substantial. The finding is consistent with the findings of previous studies such as Ilyas and Habib (2014), Gharahhajlou, Mirzaian, Hassanzadeh (2015) and Dalvand, Makvandi and Khoshli (2014).

Ilyas and Habib (2014) study explored the relationship of marital satisfaction and emotional intelligence among different professional teachers. The findings indicated significant relationship between marital satisfaction and emotional intelligence. The findings implies that married teachers with higher emotional intelligence will displayed better marital quality and is much likely to obtain marital satisfaction. Gharahhajlou, Mirzaian, Hassanzadeh (2015) investigated the relationship between emotional intelligence and marital satisfaction among high school English teachers. The results indicated a positive relationship between emotional intelligence with marital satisfaction of the teachers.

Similarly, Dalvand, Makvandi and Khoshli (2014) studied the correlation between marital satisfaction, and emotional intelligence of married university staff. The findings also indicated that there is a positive and significant correlation between marital satisfaction and emotional intelligence of the married teachers. The possible reasons behind the observed satisfying marital relation among these married teachers could be diverse. Research for instance has pointed out many associated benefits to a happy marriage, including emotional and physical health and longevity. The individual may marry for several reasons including legal, social emotional, financial, spiritual and religious purposes. There marital satisfaction however would likely depend largely on their emotional state which would reflect the perceived benefits and costs of marriage to a particular person.

Research has shown that one of the qualities common in couples who report a high degree of marital satisfaction is that they tend to consider emotionally connected to their spouse. They experience that their partner legitimately cares about them and is normally kind in their relations. Emotionally intelligent couples are conscious of what is going on in their 
partners' world and demonstrates care for that world. They are open and answer to things their mate may want from them such as a kind word, a listening ear, a gentle touch, a sensual encounter, or warm reassurance.

Research carried out by Cohen and Waldinger (2012) for instance confirmed the vital importance of emotional astuteness when he noted that the success of happiness will to some degree depend on the emotional intelligence of both the wife and the husband to gauge the emotional intimation of each partner. The reason perhaps is linked to the notion that Emotional intelligence involves the ability to reason using emotions, the ability to understand emotion and the ability to manage emotions. From Cohen and Waldinger's study, one could deduce that a satisfying marriage does not require living happy-ever, rather, it takes being able to intelligently process each other's emotional clue and talk together cooperatively about situations that may have created negative feelings.

The findings of this study is also in agreement with Anghel (2016) whose study showed significant correlations between marital satisfaction and the subcomponents of emotional intelligence like balancing personal emotions and balancing emotions of others. Therefore, being able to manage emotions would likely be helpful to play a significant role in the feelings of people about their spouse.

\section{The Relationship between the Emotional Intelligence and Marital Satisfaction of Married Male and Female Teachers in Anambra State}

Furthermore, the findings of the study revealed that there is low positive relationship existing between married male teachers' Emotional Intelligence and their marital satisfaction and a very low positive relationship of existing between married female teachers' Emotional Intelligence and their marital satisfaction. The findings further indicated that the relationship existing between emotional intelligence and marital satisfaction of married male and female teachers in Anambra State secondary schools is significant. These findings showed that an increase in the emotional intelligence of the married teachers will likely lead to a corresponding increase in the marital satisfaction of both the male and female teachers, however, the magnitude of the relationship differed significantly such that while that of male is low, that of female is very low.

These findings are consistent with findings of previous studies such as Veshki, et al. (2012) whose study noted that women with higher emotional intelligence manage their marital conflicts efficiently. The findings of the study also agreed with the finding of Anghel (2016) whose study showed that there are significant differences between married men and women satisfaction in marriage. The reason for this finding could be attributed to factors of emotionality that tend to manipulate marital satisfaction as highlighted by 
Levalekar, Kulkarni and Jagtap (2010). The study indicated that emotional management, social relationship skills and emotional sensitivity skills have significant effect in satisfaction. It was also found that in most circumstances, the level of male Emotional intelligence was responsible for couple's marital satisfaction. It is therefore possible that males possess more ability to process these seemingly complex factors of emotionality than the females.

Similarly, the study conducted by Lavalekar Kulkarni and Jagtap (2010) examined and compared the marital satisfaction and emotional intelligence of people between ages 25-65. The findings conclude a considerable gender difference on different areas of emotional intelligence, for instance; openness to criticism, self-management and empathy. A significant gender difference was also observed on two areas of marital satisfaction, sexual relations and sharing household responsibilities, that can be traced to the socio-cultural impact. The research findings thus helped in understanding the correlation of gender with core qualities of one's emotional intelligence that can affect the satisfactory marital relations.

On the other hand, the findings differed from study conducted by Agha, Mokhtaree, Sayadi, Nazer and Mosavi (2012) whose finding indicated that Overall, emotional intelligence and marital satisfaction were not linked to the variables of gender. Agha, et al. nevertheless noted that, of many aspects of marital satisfaction, interpersonal and empathy aspects were meaningfully related to the variable of gender. Also, of many aspects of emotional intelligence, the one for responsibility between men and women was only meaningfully different but the total score of emotional intelligence and marital satisfaction was not meaningfully linked to gender.

The findings of the study also varied with Hans, Mubeen, and $\mathrm{Al}$ Rabani (2013) whose study scores suggested that there is no significant difference between male and female teachers in Oman based on descriptive statistics. Additionally, Ilyas and Habib (2014) based on their study findings rejected the hypothesis that working men have better marital satisfaction as compared to married working women; no significance difference was found between both genders on marital satisfaction. The reasons for these contradicting findings could be linked to cultural differences and some other factors which may not have been covered in this study. 


\section{Conclusions}

The following conclusions are made based on the findings of this study:

The study concludes that there is a significant low positive relationship existing between married teachers' Emotional Intelligence and their marital satisfaction. Also, the relationship existing between emotional intelligence and marital satisfaction of married male and female teachers in Anambra State secondary schools is significant.This is an indication that emotional intelligence could be endowed with constructive information on couples marital relations, and that each couples ability to manage his or her emotions may likely help to play a significant role in the feelings of the married teachers about their spouse.

\section{Implications of the Study}

The findings of this study implied that emotional intelligence in marriage is one of the keys to a life-long, associated, and satisfying connection. Couples marriage could be strengthened when both a wife and a husband are eagerly conscious of their individual emotions and are able to handle those emotions in a healthy way. This also implies that there is need to prioritize marital counselling whereby the Guidance counsellors working with married people could give quality time to couples on issues regarding their marriage. Couples that are satisfied in their marriages would be guided to remain united while the couples that are dissatisfied would be assisted in their relationship.

Seminars bothering on building the emotional intelligence of both the married and intending couples could be organised by the counsellor. Moreover, married teachers who attend premarital counselling will likely have the opportunity to discuss issues that most couples argue about and most often lead to divorce or separation. Marital counselling can help the individuals address hot issues before they arise and assist them in discovering what the other person believes about the issue so that they may come to an agreement before they walk down the aisle.

\section{Recommendations}

The following recommendations were made based on the findings:

1. Married teachers should be encouraged by the Counselors involved in marital counselling to pursue habits and attitudes that promote marital satisfaction through periodic seminars and counseling sessions.

2. Government and Non-governmental organisations working in partnership with the school Guidance Counsellors should organize seminars, conference, workshops and enlightenment programmes for both intended and married teachers focusing on building emotional intelligence of the couples for satisfactory marital union. 


\section{References}

1. Agha, M.H.P., Mokhtaree, M.R. , Sayadi, A.R. , Nazer, M. \& Mosavi, S.A. (2012). Study of emotional intelligence and marital satisfaction in academic members of rafsanjan university of medical sciences. Journal of Psychology and Psychotherapy, 2(2). Retrieved from http://dx.doi.org/10.4172/2161-0487.1000106

2. Anghel, T.C. (2016). Emotional intelligence and marital satisfaction. Journal of Experiential Psychotherapy, 19(3), 14-19. Retrieved from http://jep.ro/

3. Brackett, M.A, Warner, R.M., Bosco, J.S. (2005). Emotional intelligence and relationship quality among couples. Personal relationships, 12, 197-212.

4. Egbule, J. F. (2009). Psychology of adjustment and crisis counselling. Benin: Goodnews Express.

5. Gharahhajlou, J.E., Mirzaian, B., Hassanzadeh, R. (2015). The relationship between emotional intelligence and marital satisfaction among English teachers. Turkish Journal of Scientific Research, 2(4), 91-93. Retrieved from http://www.tjsrjournal.com

6. Ilyas, S. \& Habib, S. (2014). Marital satisfaction and emotional intelligence among different professionals. International Journal of Scientific \& Engineering Research, 5(11), 302-307.

7. Ja'farzadeh F. (2011). Comparing copying styles and marital satisfaction in women based on infertility (Published M.Sc. Thesis). Allameh tabataba'I University.

8. Khorasani, N.H., Hosseini, M., Matbouei, M., Khafri, S., Vasli, P. \& Vardanjani, A.E (2015). The study of relationship between selfefficacy and marital satisfaction of couples referring to the community health centres of Babol. British Journal of Medicine and Medical Research, 19(9).

9. Lavalekar A, Kulkarni P, Jagtap, P. (2010). Emotional intelligence and marital satisfaction. Psychosocial Research, 5, 185-194.

10. Mohammadimehr, Z., \& Ayatollah K.B. (2017). The relationship between emotional intelligence, attachment styles and optimism with Martials satisfaction. Interdisciplinary Journal of Education, 1(2), 5058. Retrieved from http://www.iase-adje.ir/

11. Odebunmi, A. (2007). Parenting; A cross Cultural and Psychological Perspective Abuja: Afabunmi Nigeria Limited.

12. Ofovwe, C.E., Ofili , A.N., Ojetu , O.G. \& Okosun, F.E. (2013). Marital satisfaction, job satisfaction and psychological health of secondary school teachers in Nigeria. Health, 5(4), 663-668. Retrieved from 
13. http://dx.doi.org/10.4236/health.2013.54087

14. Omage, M.I. (2013). Critical issues in marriage failure in Benin City, Nigeria: signalling the way forward. European Scientific Journal February, 9(5). 324 - 337. Retrieved on May, 15, 2017, from http://eujournal.org/index

15. Salovey, P., Mayer, J.D. (1990) Emotional intelligence. Imagin Cogn Pers, 9, 185- 211.

16. Tamaren, K.J. (2010). Factors of emotional intelligence associated with marital satisfaction (Published Ph.D thesis), Saint Louis University, USA.

17. Zadeh, A.N. \& Tabrizi, A.M. (2014). Study predicting marriage satisfaction based on emotional intelligence, spiritual intelligence and self-efficiency. Asian Journal of Medical and Pharmaceutical Researches, 4(4), 160-166. Retrieved from http://ajmpr.scienceline.com/attachments/article/28/Asian\%20J.\%20 Med.\%20Pharm.\%20Res.\%204(4)\%20160-166,\%202014.pdf 